\title{
ASSESSMENT OF THE VEGETATION COVER CHANGE IMPACTS ON WATER EROSION, USING PAP/RAC METHOD IN UPSTREAM OF “OULJET SOLTANE" DAM, CENTRAL PLATEAU-MOROCCO
}

\author{
Youssef DALLAHI ${ }^{1}$, Ahmed OUHAMMOU ${ }^{1}$, Mohamed SBAI \\ Ahmed El ABOUDI', Amal BOUJRAF ${ }^{3}$
}

DOI: 10.21163/GT_2020.151.14

\begin{abstract}
:
The aim of this paper is to evaluate the impact of forest cover dynamics on the erosion at Kharouba watershed in the Moroccan Central Plateau. Our methodology is based on the diachronic analysis of the land cover between 1986 and 2016, using treatments of aerial photographs from 1986 and a Google Earth satellite imagery at a high resolution from 2016. The land cover maps obtained were used to establish erosion status maps between 1986 and 2016, based on methodology PAP/RAC. Our study highlights the regressive evolution of vegetation cover. This decline has stressed the increased water erosion risk in Kharouba watershed causing the spread of the areas that are vulnerable to water erosion from $36 \%$ in 1986 up to $41 \%$ in 2016.
\end{abstract}

Key-words: Vegetation cover, erosion, watershed, methodology PAP/RAC

\section{INTRODUCTION}

Soil erosion is a degradation process of natural resource that has remarkably grown over time. In fact, rapid landscape changes, due to demographic pressure and climate changes, magnify the surface runoff process, and therefore, the soil degradation (Heusch, 1970; Al Karkouri et al., 2000; Naimi et al., 2005).

In Morocco, several research studies have been dedicated to understand the erosion process in the Moroccan mountains through the modeling of soil loss in several watersheds (Laouina, 1998; Moufaddal, 2002; Damnati et al., 2013; Simonneaux et al., 2015; Iaaich et al., 2016; Briak et al., 2016).

Results, at the Beht watershed, show that the area at risk amounts to $87 \%$, with an annual siltation rate of $1.40 \mathrm{Mm} 3$ / year (El Gaatib, 2015). Kharouba watershed, located in the central part of Beht, has an average specific degradation; estimated at $4.10 \mathrm{t} / \mathrm{ha} /$ year. The outlets losses are measured at 60 thousand tons per year (HCEFLCD, 2007). This situation could pose a real threat to the siltation of the under-construction Ouljet Soultane dam.

\footnotetext{
${ }^{1}$ Cadi Ayyad University, Laboratory of Microbial Biotechnologies Agrosciences and Environment (BioMAgE), Faculty of Sciences Semlalia, Marrakech, dallahi.youssef1 @ gmail.com

${ }^{2}$ Mohammed V University, Laboratoire de Botanique et Valorisation des Ressources végétales et Fongiques (BOVAREF), Faculté des Sciences, Rabat, mohamedsbai68@gmail.com, elaboudi@gmail.com

${ }^{3}$ Ibn Tofail University, Laboratoire de Botanique, Biotechnologie et de Protection des Plantes, Département de Biologie, Faculté des Sciences, Kénitra, amal.boujraf@gmail.com
} 
This watershed has valuable forest resources covering more than $87 \%$ of its area. However, this forest patrimony suffered over time significant amount of pressures: mainly illegal logging, overgrazing and climate changes, consequently intensifying erosion and land degradation. In this context, the present work aims to highlight the gravity and the erosion phenomena evolution and to evaluate impacts of vegetation cover change on water erosion at Kharouba watershed.

\section{STUDY AREA AND DATA}

Kharouba watershed covers an area of about 19888.5 ha and is located in the central part of Beht (Fig. 1 and 2). It is characterized by the dominance of primary geological formations. The area has an accentuated relief, a semi-arid to sub-humid climate, marked by strong spatial and temporal rain variability. These factors associated with land use and anthropogenic actions promote its vulnerability to erosion.

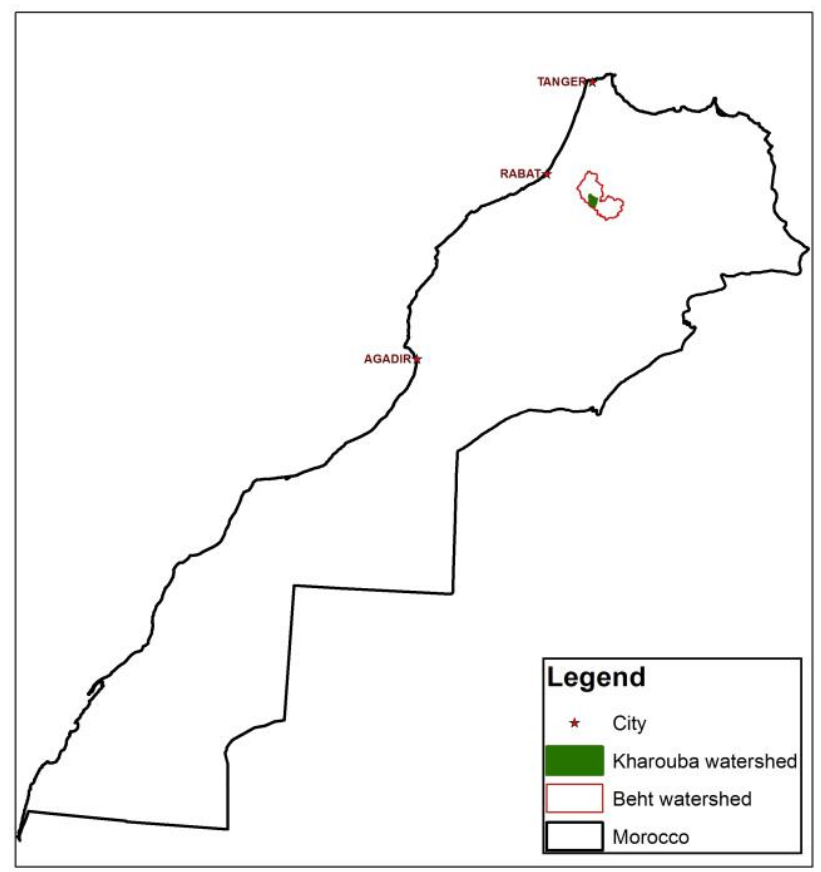

Fig. 1. Location Map of the studied area.

The average specific degradation for Kharouba watershed is estimated at $4.10 \mathrm{t}$ /ha/year. Losses at the watershed outlet are estimated at 60 thousand tons per year (HCEFLCD, 2007). In terms of land use, Kharouba watershed is dominated by forest formations covering more than $87 \%$ of its area (Fig. 3). These formations are mainly based on Tetraclinis articulata and Quercus rotundifolia (Dallahi et al., 2016; Dallahi et al., 2017). 


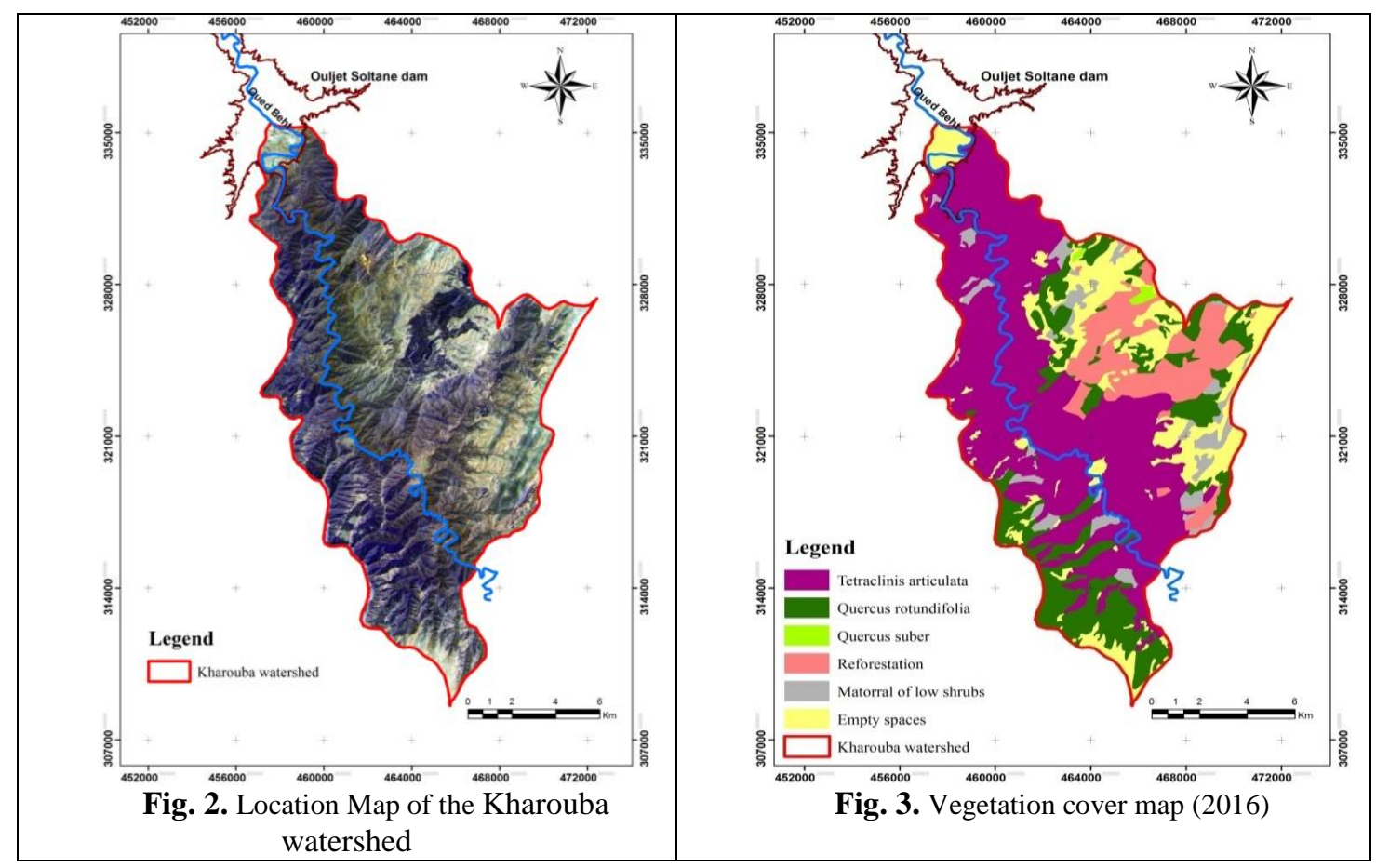

\section{METHODOLOGY}

From a methodological approach, this work consists, firstly, in a diachronic analysis of the vegetation cover using aerial photographs from 1986 and a Google Earth satellite imagery at a high resolution from 2016 to quantify the spatio-temporal dynamics of the vegetation cover. Secondly, we relied on the predictive approach of the PAP / CAR method (PAP/RAC, 1997), to set up an erosion status map on two different dates, providing thus the map canvas of the potential and the general patterns of erosion.

The predictive approach of the PAP/RAC method is mainly a data processing according to the following operations (Fig. 4):

- Slope and lithofacies mapping;

- Erodibility mapping by overlaying the slope and the lithofacies maps;

- Land and vegetation cover mapping for 1986 and 2016;

- Soil protection maping of 1986 and 2016 by overlaying the land and vegetation cover maps;

- Erosion status mapping by overlaying erodibility and soil protection level maps. 


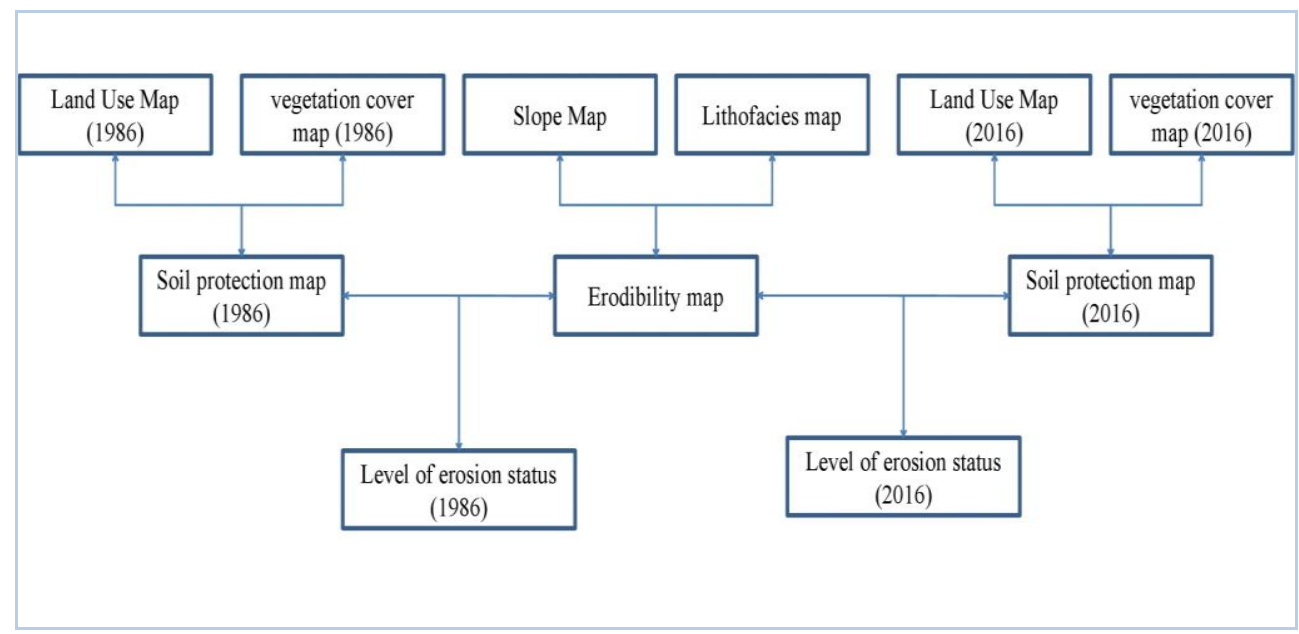

Fig. 4. Main operational sequence of erosion mapping procedures (PAP/RAC, 1997).

\section{RESULTS AND DISCUSSIONS}

\subsection{Results of the vegetation diachronic analysis}

The diachronic analysis is based on the comparison of the composition and the surface of the plant's formations on two different dates. The different area's loss and gain in term of strata are shown in Table $\mathbf{1 .}$

Table 1.

Confusion matrix for mapping land cover change.

\begin{tabular}{|c|c|c|c|c|c|c|c|c|}
\hline & \multicolumn{9}{|c|}{$\mathbf{1 9 8 6}$} \\
\hline & strata & Ta & Qr & Qs & R & M & V & Total (2016) \\
\cline { 2 - 9 } & Ta & 10898 & 0 & 0 & 0 & 0 & 0 & 10898 \\
\cline { 2 - 9 } & $\mathbf{Q r}$ & 0 & 2559 & 0 & 0 & 0 & 0 & 2559 \\
\cline { 2 - 9 } $\mathbf{0}$ & $\mathbf{Q s}$ & 0 & 0 & 97 & 0 & 0 & 0 & 97 \\
\cline { 2 - 9 } $\mathbf{1}$ & $\mathbf{R}$ & 303 & 655 & 0 & 1150 & 54 & 0 & 2162 \\
\cline { 2 - 9 } & $\mathbf{M}$ & 730 & 212 & 2 & 0 & 145 & 0 & 1089 \\
\cline { 2 - 9 } & Total (1986) & 14560 & 3617 & 109 & 1207 & 208 & 186 & 3082 \\
\hline
\end{tabular}

The table analysis exhibits the significant regression that the different plant formations have experienced. Indeed:

- The Tetraclinis articulata (Ta) area declined from 14560 ha in 1986 to 10898 ha in 2016, a fall of $25 \%$. Its average regression rate is 118 ha/year. Empty spaces and matoral of low shrubs took over this stratum superficy.

- Quercus rotundifolia (Qr) reported a $34 \%$ reduction in 2016 compared to 1986. The regression pace is up to 34 ha. The majority of this stratum was planted by Pinus Pinaster (R). 
- Quercus suber (Qs) declined by 12 ha, or $11 \%$ of its area. It has been largely transformed to empty spaces.

- The matorral (M) benefited from the forest trees degradation, it gained an area of 881 ha. Their average growth rate is estimated at $28 \mathrm{ha}$ /year.

- Empty land (V) increased over an area of 2896 ha. Their extension is mainly at the expense of Tetraclinis articulata and Quercus rotundifolia.

\subsection{Soil protection maps analysis}

Each type of vegetation cover provides a degree of soil protection that corresponds to a specific class. The Soil Protection Map reflects the type and the density of the vegetation cover in Kharouba watershed.

The diachronic analysis of Kharouba watershed's soil protection map, between 1986 and 2016, exhibit the regressive evolution that the vegetation cover has undergone a in terms of area and especially density. Indeed, the high-density vegetation is declining in favour of an average or even low vegetation cover density. This regression mainly concerned the high density Tetraclinis articulata whose surface area has been slashed from around 2699 to 760 ha.

This situation has led to the increase in areas of low to very low protection, which expanded from $26 \%$ of the total watershed area in 1986 to $33 \%$ in 2016. On the other hand, the high and very high protection levels have a regressive evolution, their percentages dropped from $51 \%$ in 1986 to $47 \%$ in 2016 (Fig. 5 and 6). This regressive evolution of the soil protection levels is the result of several factors including illegal logging, overgrazing and climate changes.

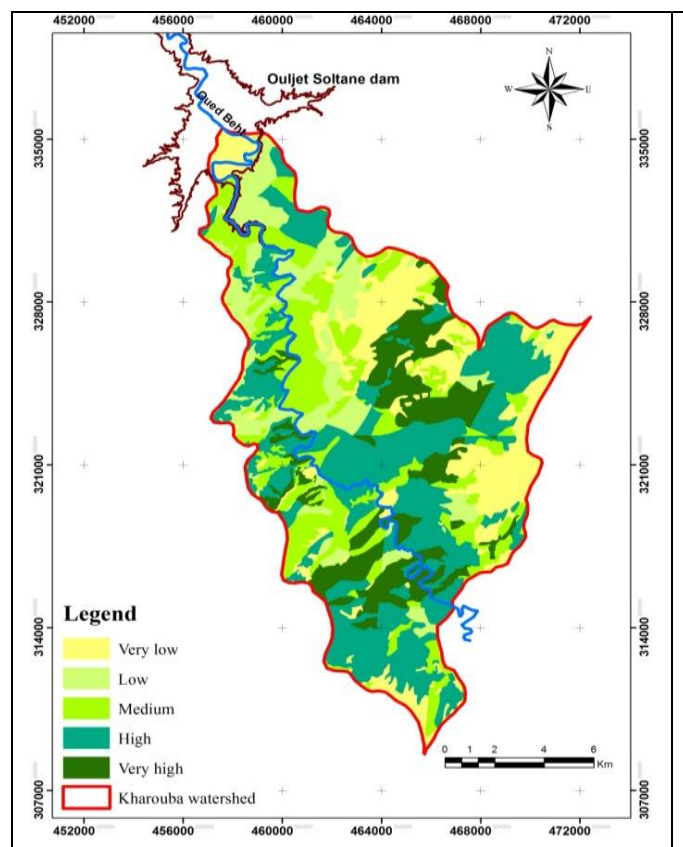

Fig. 5. Soil protection map (2016)

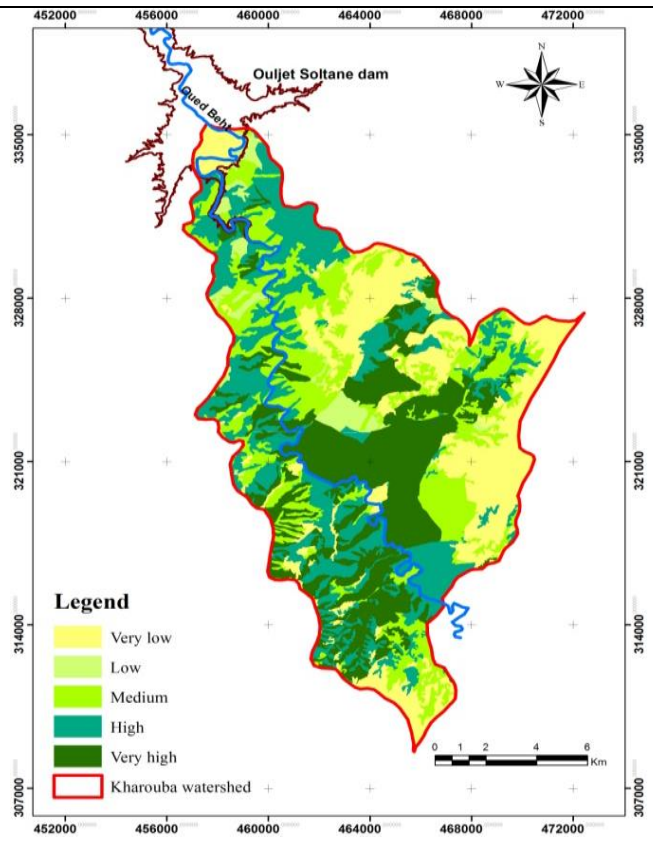

Fig. 6. Soil protection map (1986) 
The analysis of the soil protection levels' distribution depending on the vegetation cover nature and density shows that soils with high protection are mainly located in Tetraclinis articulata and in dense to medium-dense Quercus rotundifolia forests with a very developed undergrowth. However, the low protection soil can be found in very degraded rangelands, bare soils and bad-lands.

\subsection{Erodibility map analysis}

The distribution analysis of the erodibility levels (Fig. 7 and 8) reveals that the most representative class is the one belonging to the strong class with $38 \%$ of the total study area, followed by the class of medium erodibility whith $26 \%$. On the other hand, low to moderate erodibility affects only $18 \%$ of the total kharouba Watershed area.

In addition, the erodibility map indicates that zones where the slope is steep, erodibility is always high to extreme. This can notably be observed at the southern and south-eastern part of the watershed. However, in the north, north-west and the middle of the watershed, the situation is less worrying due to the dominance of weak to moderate levels of erodibility.

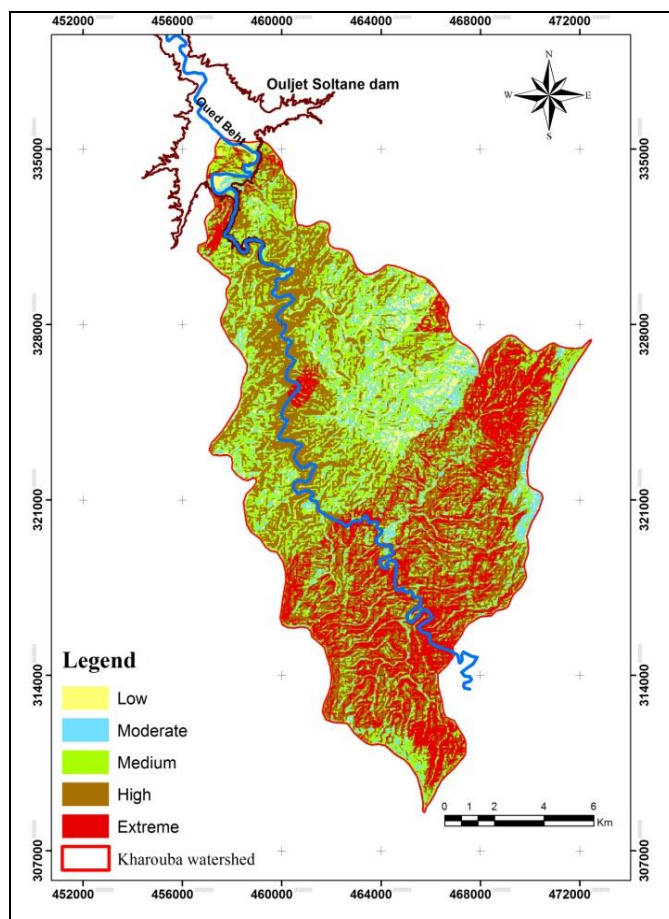

Fig. 7. Erodibility map

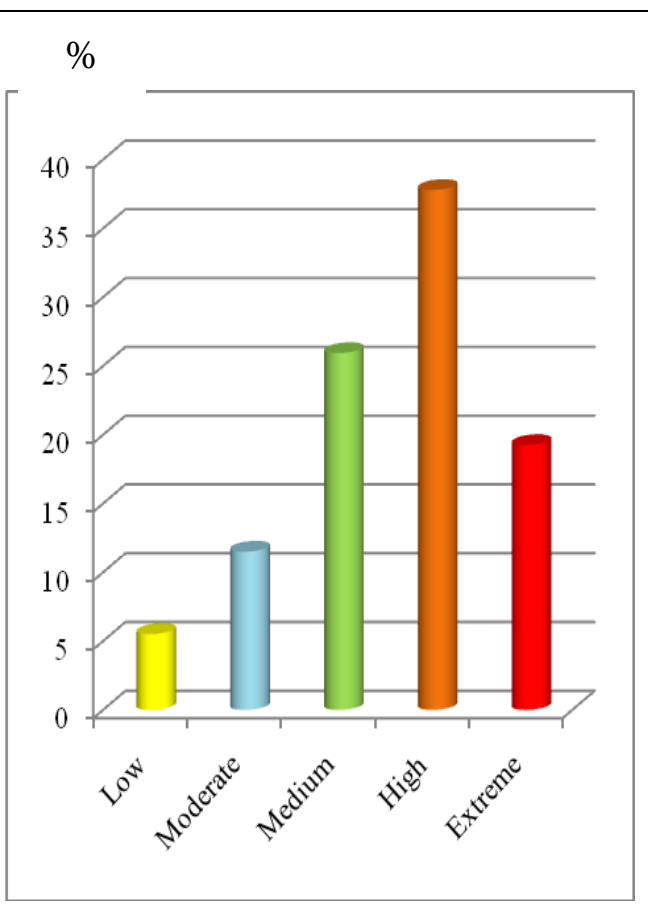

Fig. 8. Levels of erodibility

\subsection{Erosion status map analysis}

The mapping of the erosion states of 1986 and 2016 is obtained by overlaying erodibility and soil protection level maps of 1986 and 2016. The erosional status maps 
analysis (Fig. 9 and 10) shows that erosion is active and apparent over more than $63 \%$ of the total watershed area. It takes different kinds of erosion, including sheet erosion and gullying.

Areas of high erosive risk correspond particularly to rough terrain with fairly high soil friability rate and low to very low recovery rate.

The dynamics of erosion status analysis exhibit an increase of the high and extreme states expanding from $36 \%$ of the total area in 1986 to $41 \%$ in 2016. This increase mainly concerned the southern and northern part of Kharouba watershed, more particularly in areas where the vegetation cover and notably Tetraclinis articulata was severely degraded, in addition to the zones at the edge of Oued Beht. This is due to the dominance of sedimentary formations. Similarly, the erosion map analysis shows that areas marked by important vegetation cover are not very sensitive to erosion.

Our results highlight the predominant role of the vegetation cover in the overall decrease of the erosion rate. This vegetation protects the soil surface against the raindrops impact, slows down the speed of runoff water and maintains good soil porosity, making it highly resistant to erosion (Sabir et al., 1994; Zhou et al., 2008; Fletcher, 2017; Hou et al., 2016).

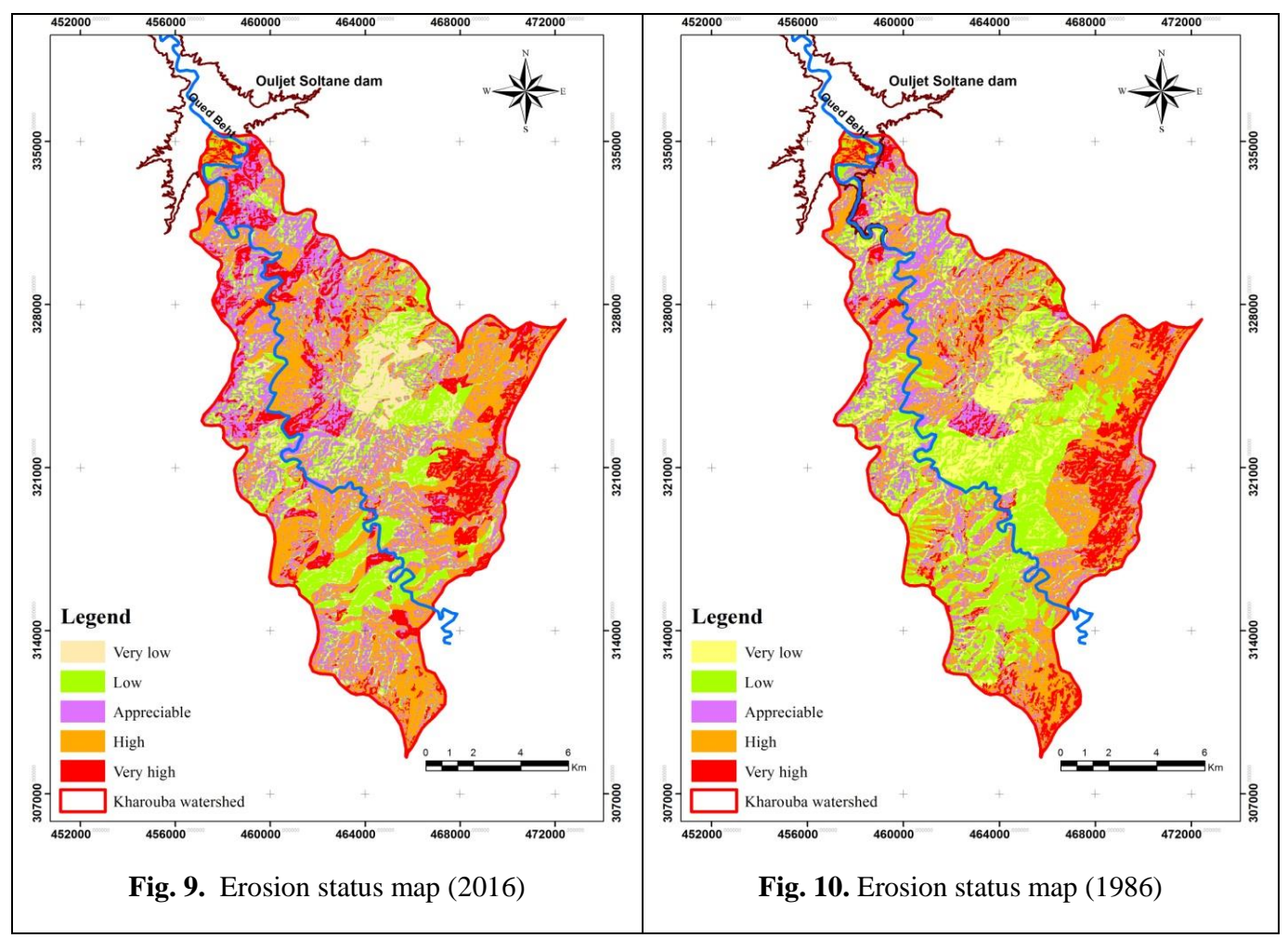




\section{CONCLUSIONS}

Kharouba watershed, in upstream of "Ouljet Soltane" dam, covers an area of about 19 888.50 hectares and is largely dominated by forests along with land suitable for grazing and uncultivated land. It offers valuable forest resources due to its rich floristic diversity.

The evaluation of the forest cover dynamics impacts on water erosion in this watershed pinpoints the regressive evolution of the vegetation cover between 1986 and 2016. This decline has stressed the increased water erosion risk in Kharouba watershed causing the expansion of areas that are vulnerable to water erosion from $36 \%$ in 1986 to $41 \%$ in 2016.

Given the situation, it is necessary to intervene to fight against erosion, based on an innovative approach that relies on the improvement of the living conditions of the local population in order to reduce the pressure on the forest resources while ensuring their conservation and development.

\section{R E F E R E N C E S}

Al Karkouri, J., Laouina, A., Roose, A. \& Sabir M. (2000) Capacité d'infiltration et risques d'érosion des sols dans la vallée des Beni Boufrah Rif central (Maroc). Bulletin du Réseau Erosion, 20, 342-356.

Briak, H., Moussadek, R., Aboumaria K. \& Mrabet R. (2016) Assessing sediment yield in Kalaya gauged watershed (Northern Morocco) using GIS and SWAT model. International Soil and Water Conservation Research. International Soil and Water Conservation Research, 4(3), 177-185.

Da Cruz, D.C., Benayas, J.M.R., Ferreira, G.C., Monteiro, A.L., Schwartz, G. (2019) Evaluation of soil erosion process and conservation practices in the Paragominas-pa municipality (Brazil). Geographia Technica, 14(1), 14-35, DOI: 10.21163/GT_2019.141.02

Dallahi Y., El aboudi A. \& Aafi A. (2016) A contribution to the knowledge of the Moroccan Central Plateau plant communities. Plant Sociology, 53 (2), 41-46.

Dallahi Y., El aboudi A., Aafo A. \& Belghazi B. (2016) Inventory of medicinal plants in the Site of Biological and Ecological Interest of Kharouba (Central Plateau, Morocco). J. Mater. Environ. Sci.,7 (11), 3993-3999.

Dallahi, Y., Chahhou, D., El Aboudi \& A., Aafi, A. (2017) Distribution Mapping and chemical composition of Tetraclinis articulata (Vahl.) Masters in the Site of Biological and Ecological Interest of Kharouba (Central Plateau, Morocco). Journal of Materials and Environmental Science, 8 (7), 2474-2479.

Damnati, B., Sanaa, I. \& Radakovitch, O. (2013) Quantifying erosion using $137 \mathrm{Cs}$ and $210 \mathrm{~Pb}$ in cultivated soils in three Mediterranean watersheds: synthesis study from El Hachef, Raouz and Nakhla (North West Morocco). Journal of African Earth Sciences, 79, 50-57.

El Gaatib, R., Larabi, A. \& Faouzi M. (2015) Integrated elaboration of priority planning of vulnerable areas to soil erosion hazard using Remote Sensing and GIS techniques: A pilot case of the Oued Beht Watershed (Morocco). Journal of Materials and Environmental Science, 6 (11), 3110-3127.

Fletcher, W.J. (2017) Anthropogenic trigger for Late Holocene soil erosion in the Jebel Toubkal, High Atlas, Morocco. Catena, 149 (3), 713-726.

HCEFLCD (2007) Plan d'Action du Haut Commissariat aux Eaux et Forêts et à la Lutte Contre la Désertification, 11-13.

Heusch, B. (1970) L'érosion du Pré-Rif. Une étude quantitative de l'érosion hydraulique dans les collines marneuses du Pré-Rif occidental. Annales de la recherche forestière, 12, 9-176.

Hou J., Wang H., Fu B., Zhu L., Wang Y. \& Li Z. (2016) Effects of plant diversity on soil erosion for different vegetation patterns. Catena, 147, 632-637.

Iaaich H., Moussadek R., Baghdad B., Mrabet R., Douaik A., Derradji A. \& Bouabdli A. (2016) Soil erodibility mapping using three approaches in the Tangiers province, Northern Morocco. 
International Soil and Water Conservation Research. International Soil and Water Conservation Research, 4, 159-167.

Laouina, A. (1998) Dégradation des terres dans la région méditerranéenne du Maghreb. Bulletin du Réseau Erosion, 18, 33-53.

Moufaddal, K. (2002) Résultats des parcelles d'érosion dans le bassin versant de l'oued Nakhla,Maroc. Bulletin du Réseau Erosion, 21, 244-254.

Naimi, M., Tayaa, M., Ouzizi, S. (2005) Cartographie des formes d'érosion dans le bassin-versant de Nakhla (Rif occidental, Maroc). Secheresse, 16, 79-82.

PAP/RAC (1997) Guidelines for mapping and measurement of rainfall-induced erosion processes in the Mediterranean coastal areas. PAP-8/PP/GL.1, Priority Actions Programme Regional Activity Centre (MAP/UNEP), with the co-operation of FAO : XII, $70 \mathrm{p}$.

Sabir, M., Merzouk, A., Berkat, O. \& Roose, E. (1994) Effet du pâturage sur l'état de surface, l'infiltrabilité et la détachabilité du sol dans un milieu pastoral aride (Aarid, Haute Moulouya, Maroc). Bulletin du Réseau Erosion, 14, 444-462.

Simonneaux, V., Cheggour, A., Deschamps, C., Mouillot, F., Cerdan, O. \& Le Bissonnais, Y. (2015) Land use and climate change effects on soil erosion in a semi-arid mountainous watershed (High Atlas, Morocco). Journal of Arid Environments, 122, 64-75.

Suwarno, Sutomo, Aditama, M.R. (2019) The analysis of the landslide vulnerability sub watersheds Arus in Banyumas Regency. Geographia Technica, 14(2), 112-119, DOI:10.21163/GT_2019.142.10

Zhou, P., Luukkanen, O., Tokola, T. \& Nieminen, J. (2008). Effect of vegetation cover on soil erosion in a mountainous watershed. Catena, 75 (3), 319-325. 